from explanted aortas $(\mathrm{p}<0.05)$. Explanted aortas from Nox2-Tg had significantly higher levels of secreted pro-inflammatory cytokine, cyclophilin A (Сура) at both baseline and after 5 days of in vivo AngII treatment compared to WT littermates. Compared to primary WT EC and VSMC, Nox2-Tg primary EC, but not primary VSMC, had increased ROS production which was accompanied by increased Cypa secretion and ERK1/2 activation. Furthermore, conditioned media from Nox2-Tg EC induced a greater ERK1/2 phosphorylation compared to the media of WT controls. In conclusion, we demonstrate for the first time that a specific increase in endothelial ROS through the over-expression of Nox2 is sufficient to induce aortic dissection in response to AngII stimulation. Endothelial secreted Cypa could be the signalling mechanism by which increased endothelial ROS regulates the inflammatory response and the susceptibility to aortic dissection.

\section{ENDOTHELIUM SPECIFIC INSULIN RESISTANCE LEADS TO ACCELERATED ATHEROSCLEROSIS: A ROLE FOR REACTIVE OXYGEN SPECIES}

doi:10.1136/heartjnl-2012-301877a.4

${ }^{1} \mathrm{M} C$ Gage, ${ }^{* 1} \mathrm{~N}$ Y Yuldasheva, ${ }^{1} \mathrm{H}$ Viswambharan, ${ }^{1} \mathrm{P}$ Sukumar, ${ }^{1} \mathrm{R} \mathrm{M}$ Cubbon, ${ }^{1} S$ Galloway, ${ }^{1} \mathrm{H}$ Imrie, ${ }^{1} \mathrm{~A}$ Skromna, ${ }^{1} \mathrm{~J}$ Smith, ${ }^{2} \mathrm{C}$ Jackson, ${ }^{1} \mathrm{M} \mathrm{T}$ Kearney, ${ }^{1} S$ B Wheatcroft. 'Leeds University, Leeds, UK; ${ }^{2}$ Bristol Heart Institute, University of Bristol, Bristol, UK

Background Global insulin resistance and endothelial dysfunction have been identified as predisposing factors for atherosclerosis. However, it is unclear whether selective insulin resistance in endothelial cells alone, is sufficient to promote atherosclerosis. We addressed this question by crossing Endothelial Specific Mutant Insulin Receptor Over-expressing (ESMIRO) mice with $\mathrm{ApoE}^{-/-}$ mice. ESMIRO mice over-express a human insulin receptor with an Ala-Thr1134 mutation in the tyrosine kinase domain (which disrupts insulin signalling) selectively in endothelial cells under the control of the tie- 2 promoter/enhancer.

Methods Male ApoE $E^{-/} /$ESMIRO mice were compared with sexmatched littermate ApoE ${ }^{-/-}$mice (both on a C57B16 background) after feeding a Western-style diet for 12 weeks.

Results $\mathrm{ApoE}^{-/-} / \mathrm{ESMIRO}$ mice were morphologically indistinguishable from $\mathrm{ApoE}^{-/-}$control littermates and showed normal development with no differences between groups in body mass. Heart rate, systolic blood pressure, glucose tolerance, insulin sensitivity and fasting glucose levels were similar in $\mathrm{ApoE}^{-/} / \mathrm{ESMIRO}$ and $\mathrm{ApoE}^{-/-}$mice. ApoE ${ }^{-/-} / \mathrm{ESMIRO}$ cultured endothelial cells demonstrated insulin resistance through significantly reduced insulin mediated eNOS activity $(p=0.003)$. Aortic lipid deposition along the whole aorta, assessed by en-face oil red $O$ staining, was similar in $\mathrm{ApoE}^{-/-}$ESMIRO and $\mathrm{ApoE}^{-/-}$mice $(6.4 \% \pm 0.5 \%$ vs $5.8 \% \pm 0.5 \%$; $\mathrm{p}=0.39$ ). Analysis of lipid deposition along the lesser curvature of the aortic arch revealed a significant increase in $\mathrm{ApoE}^{-/}-\mathrm{ESMIRO}_{\text {when }}$ compared to controls $(9.4 \pm 0.89$ vs $12.43 \pm 1.19 \% p=0.035)$. Atherosclerotic lesion area in cross sections of aortic sinus was also significantly increased in $\mathrm{ApoE}^{-/-} / \mathrm{ESMIRO}$ mice compared to ApoE $\mathrm{E}^{-/-}$ controls $(24.8 \% \pm 2.4 \%$ vs $16.6 \% \pm 2.4 \%$; $p=0.02)$. Vascular function assessed through relaxation responses of aortic rings in response to the endothelial specific vasodilator acetylcholine revealed that aortic rings from $\mathrm{ApoE}^{-/-} / \mathrm{ESMIRO}$ mice had blunted relaxation responses to acetylcholine (Emax ApoE $\mathrm{E}^{-/-}$102.88 \pm , Emax $\mathrm{ApoE}^{-/} /$ESMIRO $65 \pm 41 \%, p=0.02$ ), which was restored by the superoxide dismutase mimetic and antioxidant MnTMPyP (Emax $\mathrm{ApoE}^{-/-} / \mathrm{ESMIRO}$ without MnTMPyP $65 \pm 41 \%$, with MnTMPyP $112 \pm 15 \%$ p=0.048). Endothelial cells from $\mathrm{ApoE}^{-/-} / \mathrm{ESMIRO}$ mice had significantly increased basal generation of superoxide (1.87-fold increase compared to $\left.\mathrm{ApoE}^{-/-} \mathrm{p}<0.05\right)$ which was blunted by the selective NADPH oxidase inhibitor gp91ds-tat $(11 \%$ reduction $\pm 0.02, p=0.03)$ and the non-selective NO synthase inhibitor L-NMMA ( $6 \%$ reduction \pm 0.01 $\mathrm{p}=0.03$ ).

Conclusions Endothelial specific insulin resistance is sufficient to promote atherosclerosis and increase lesion area in ApoE null mice potentially via the increased ROS displayed in this model. This suggests that enhancing endothelial insulin sensitivity may be an appropriate target to prevent atherosclerosis in insulin-resistant conditions.

\section{E RIGHT VENTRICULAR ORIGIN OF ARRHYTHMIAS IN SCN5A+/- MICE IS DUE TO REDUCED NA+ AND HIGHER $\mathrm{K}+$ CHANNEL EXPRESSION AND FUNCTION}

doi:10.1136/heartjnl-2012-301877a.5

${ }^{1} \mathrm{C}$ A Martin, ${ }^{2} \mathrm{U}$ Siedlecka, ${ }^{3} \mathrm{~K}$ Kemmerich, ${ }^{4} \mathrm{~J}$ Lawrence, ${ }^{2} \mathrm{~J}$ Cartledge, ${ }^{1} \mathrm{~L}$ Guzadhur, ${ }^{4} \mathrm{~N}$ Brice, ${ }^{1} \mathrm{~A}$ A Grace, ${ }^{1} \mathrm{C}$ Schwiening, ${ }^{2} \mathrm{C} \mathrm{M}$ Terracciano, ${ }^{1} \mathrm{C}$ L-H Huang. ${ }^{1}$ University of Cambridge, Cambridge, UK; ${ }^{2}$ Heart Science Centre, Imperial College London, London, UK; ${ }^{3}$ Medical Research Council, Laboratory of Molecular Biology, Cambridge, UK; ${ }^{4}$ Takeda Cambridge Limited, Cambridge, UK

Introduction Brugada syndrome is associated with ventricular tachycardia originating in the right ventricle (RV); this has been
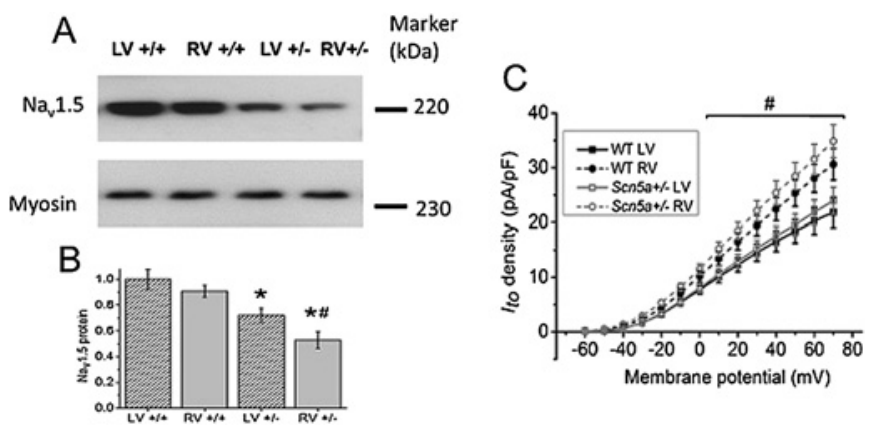

Abstract E Figure 1

A LV RV
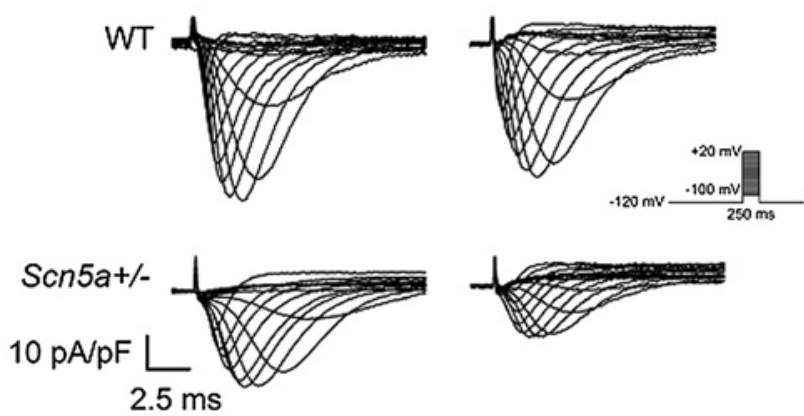

B

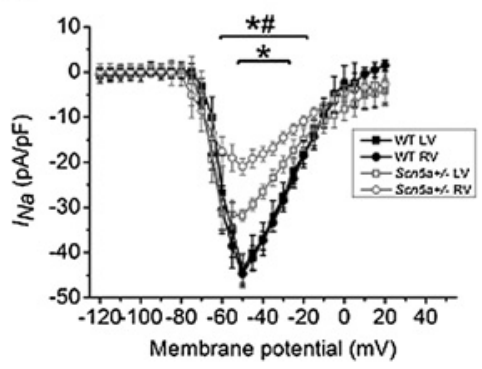

C

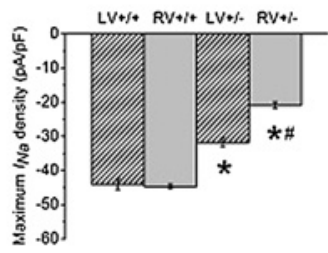

Abstract E Figure 2 
attributed to either depolarisation abnormalities or increased repolarisation heterogeneities. We have used a heterozygotic $\operatorname{Scn} 5 a+/-$ murine model to investigate the underlying mechanisms for the predisposition of the RV to arrhythmias.

Methods and Results $\mathrm{Na}_{\mathrm{v}} 1.5$ mRNA and protein expression were lower in Scn5a+/- than wild-type (WT) hearts, with a further reduction in the RV compared to left ventricle (LV) (Abstract $E$ figure $1 \mathrm{~A}, \mathrm{~B}, \mathrm{n}=4$, significant differences: * $=\mathrm{WT}$ vs $\operatorname{Scn} 5 \mathrm{a}+$ /-; \# $=\mathrm{LV}$ vs RV). There were higher expression levels of $\mathrm{K}_{\mathrm{v}} 4.2, \mathrm{~K}_{\mathrm{v}} 4.3$ and $\mathrm{KChIP}_{2}$ in $\mathrm{RV}$ than $\mathrm{LV}$ in both groups. Action potential (AP) upstroke velocity was decreased in $S \mathrm{cn} 5 \mathrm{a}+$ /- (RV: $59.43 \pm 2.70 \mathrm{~V} / \mathrm{s}$ to $30.26 \pm 4.03 \mathrm{~V} / \mathrm{s}$, $\mathrm{p}<0.0001, \mathrm{n}=20$ ), and furthermore was smaller in RV than LV. AP durations were smallest in the RV of $\operatorname{Scn} 5 a+/-$ myocytes. RV transient outward current density $\left(I_{t o}\right)$ was greater than LV in both WT and $\operatorname{Scn} 5 a+/-$ (Abstract E figure 1C, $\mathrm{n}=17$ ), with similar voltage dependence of activation. Time constants of inactivation were larger in RV than LV, and voltage dependence of inactivation was shifted to more negative values in RV compared to LV, but to more positive values in $\mathrm{Scn} 5 a+/$ - compared to WT. Maximum $\mathrm{Na}^{+}$current density $\left(I_{\mathrm{Na}}\right)$ was decreased in $\mathrm{Scn} 5 a+/-$, with a further reduction in the RV (Abstract E figure 2A-C, $n=17$ ). Voltage dependence of activation was unchanged, but inactivation was shifted to more negative values in $\mathrm{Scn} 5 \mathrm{a}+/-$. Maximum persistent $\mathrm{Na}^{+}$current density $\left(I_{p \mathrm{Na}}\right)$ was decreased in a similar pattern to $I_{\mathrm{Na}}(\mathrm{RV}:-0.30 \pm 0.03 \mathrm{pA} / \mathrm{pF}, \mathrm{n}=15 \mathrm{vs}$ $-0.17 \pm 0.02 \mathrm{pA} / \mathrm{pF}, \mathrm{n}=22, \mathrm{p}=0.0009)$.

Conclusion Our findings show preferential upregulation of the single Scn5a gene in the LV of the Scn5a+/- mice compared to RV. The reduced expression of $\mathrm{Na}^{+}$channels in RV leads to smaller $I_{\mathrm{Na}}$, resulting in slowed conduction, and smaller $I_{p N a}$, which in combination with increased $I_{t o}$, results in shorter AP durations and greater heterogeneity of repolarisation, thus suggesting arrhythmogenesis may be initiated by both abnormal depolarisation and repolarisation in the RV of Scnsa+/- hearts. Insight into the molecular mechanisms of arrhythmias could prove crucial in planning possible new pharmacological therapies for a disease where the mainstay of treatment is cardioverter-defibrillator implantation. 